\title{
Researches on the Construction of Modern Agricultural Information Service System under "Internet +" Environment
}

\author{
Zhanjun Ma \\ The College of Information Engineering, Shaanxi Institute of International Trade and Commerce, \\ Xi'an, 712046, China
}

Keyword: "Internet+", Modern agriculture, Information service system.

\begin{abstract}
During the development progress of modern society, information construction has played a quite important role. In the modern agricultural development, the agriculture is the major information, which can solve the problems during the development of agriculture. In this paper, based on the "Internet+" environment, it has offered quite beneficial fundamental conditions for setting up modern agricultural information service system.
\end{abstract}

\section{Introduction}

With the development of Three Rural Issues (referring to agriculture,rural areas and farmers), under the "Internet+" background, the agricultural informatization problem has aroused people's general concerns. In order to promote the development of agricultural informatization, on the basis of constructing implementation platform, according to relevant experiences and lessons, it still needs to promote the agricultural informatization construction and service.

\section{Construction of Modern Agricultural Information Service System Under the "Internet+" Environment}

The modern agricultural information service system includes five core modules, which can offer a comprehensive solution for the agricultural informatization construction and development, further to ensure the effective implementation and promote the formation of "Internet+" Internet of Things. There is great relationship with agricultural information service, e-commerce and comprehensive service, further to construct an unified and integrated "Internet+" agricultural information service system.

\section{Agricultural Informatization Construction}

The core of modern agricultural information service is the construction and development of informatization, which is the main part of system construction. During the construction period of agricultural informatization, it has taken agricultural information technology as the basis of implementation. In agricultural activities, the information flow has been adjusted and controlled throughout the process. Meanwhile, it has taken the information and knowledge inputs as the key points, which offers beneficial basis for the agricultural development in the new period. It is also a major stage during the progress of modern agricultural development. With gradual progress and development of modern informatization construction, it cannot only reform the traditional agricultural development, increase the level of information technology service, but also give full play to Three Rural Issues, reasonably solve the contradiction between small farmers and big market. Under the circumstance, it cannot only narrow the gap between urban and rural areas, but also change 
the information poverty in rural areas, which has great significance for the social development in modern times.

\section{“Internet+" and Agricultural Internet of Things}

Internet of Things has run throughout the development of system. For instance, it spreads all over hardware product, software product, agriculture, aquaculture industry, etc. Of which, hardware products mainly refer to sensors, which collect information and test equipment. As the hardware product, it refers to the cloud calculation and big data informatization system. As the agricultural industry and aquaculture industry, it can offer scientific and reasonable solutions by taking advantage of Internet of Things, so as to maintain the quality and safety of products. Therefore, based on the internet and Internet of Things, it can offer innovative development fields for the modern social development. During the operational process, agricultural Internet of Things can be improved from three aspects. First of all, it could realize all-around perception. By taking advantage of sensor and QR code, information can be acquired anywhere, anytime. Secondly, it should be equipped with reliable transmission mode. By taking advantage of internet and communication network, both of them can be developed together. During the process of information transmission, it can guarantee the authenticity and reliability of acquired information. Thirdly, intelligent work can be realized. By utilizing some intelligent technologies, such as cloud computing, it can accurately analyze and process a large amount of information and data, further to promote the completion of intelligent control. For instance, the research and design of agricultural information communication network has just adopted the intelligent devices and software products of Internet of Things. During the operational process of agricultural information communication network, firstly, it has adopted advanced sensor technology, collected the agricultural breeding and planting information, and also promoted the accuracy of acquire information. Besides, it can make comprehensive analysis on these information, so as to guarantee that efficient countermeasures can be supplied at last. Meanwhile, it can also offer information services for the governmental decisions, management of enterprises and agricultural production work, further to guarantee the quality and safety of products. Targeted at some problems during the breeding and planting process, it can also offer remote diagnosis, guarantee to offer information services. In this way, it cannot merely promote the stable increase of labour efficiency, but also lower the risks during the agricultural production process.

\section{Agricultural Information Service}

With the progress and development of modern society, Chinese agriculture and rural areas have realized informatization development, which promote the efficient utilization of information technology. Meanwhile, China has also put forward the development strategy of agricultural informatization. Traditionally,the informatization development cannot realize the overall planning, the information share is also confronted by large difficulties and the development of information timeless is greatly restricted. Therefore, based on all websites, CMCC and China Unicom, the agricultural information service system can be constructed. It also guarantees to utilize new modern technologies, especially the cloud technology and internet technology, further to promote efficient implementation. By applying the new technologies to the agriculture managing bodies, cooperative organizations and farmers, it can guarantee the formation of agricultural information service system. During the period, farmers can share information anytime, anywhere, who can also offer personalized services for themselves. As shown in the picture, it is the agricultural information service system ${ }^{[1]}$. 


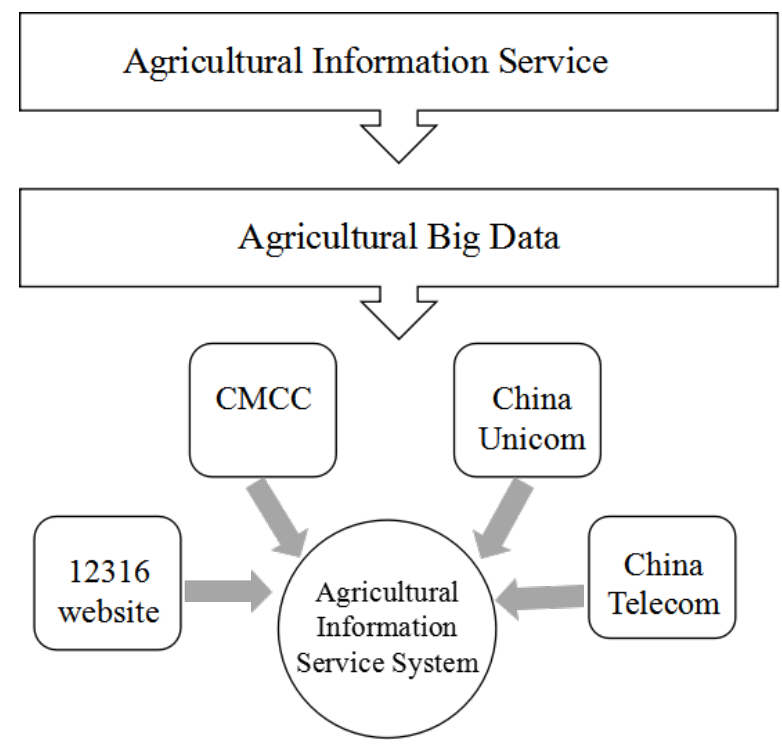

\section{Agricultural E-commerce}

According to relevant statistics and analysis of internet information center, there were 195 million rural network users by 2015, occupying $28.4 \%$ of all. Meanwhile, urban network users achieved $71.6 \%$. Compared to the development scale of 2014, it increased by $4.8 \%$. By comparing the development scale of network users to the urban areas, the growth rate is much faster. Based on the network consumption, it achieves a quite high value as well. In China, the distribution of rural population is rather wide, but they are backward in transportation. Thus there are great challenges faced by modern countryside in logistics distribution and after-sales services. Such a phenomenon enables the $\mathrm{O} 2 \mathrm{O}$ mode to give full play to its own advantages. Under the "Internet+" environment, with the construction of modern agricultural information service system, it cannot only develop the e-commerce, but also set up the online electronic information transaction platform. During the process of e-commerce service, it promotes the positive development of businesses. In rural areas, the consumers cannot well accept the online shopping. Meanwhile, being limited by logistics and payments, there is great development lag. Therefore, in order to realize home delivery service and home-entry maintenance, it needs to change their own concepts of rural consumers, further to guarantee that e-commerce can be positively introduced into the rural markets. For instance, Yinong Cooperative has obtained huge development in the pilot work of home-entry agricultural information. The agricultural department has played a leading role and taken the initiative to call at peasant households for the pilot work. It cannot realize the balanced development between urban and rural areas, but also promote efficient utilization and services of agricultural information resources. Moreover, Yinong Cooperative can also provide great conveniences for peasants. Due to quite good services, it can promote the effective application of modern information technology, provide good services for production and payment in rural areas, so as to let farmers realize modern development, create convenient and comfortable development space, offer comprehensive agricultural management philosophies and promote efficient development of information services ${ }^{[2]}$.

\section{Comprehensive Service}

During recent years, with continuous progress and development, tourism agriculture and rural agriculture have occupied the tourism information plates. There are more and more obvious development tendencies. China is a great developing agricultural country, which possesses quite rich agricultural resources. Rural areas have colorful customs and unique folk arts, which are important components of agricultural tourism. In modern society, the urban life is stressful. Besides, the environmental pollution has been aggravated. More and more people long for the country life, further to promote the progress and development of agricultural tourism. With the development of 
agricultural tourism, it cannot only increase more economic profits for farmers, improve the growth rate of agriculture, but also increase the employment efficiency of farmers. Agricultural products have been largely developed, especially some agricultural products with characteristics. The quantity of sale has kept growing. Meanwhile, agricultural tourism has also promoted the progress and development of other industries. With continuous progress and development of agricultural tourism, it has attracted a lot of investments and promoted the transition and development of rural areas. Under such a background, based on the "Internet+" environment, urban and rural mobile terminal has been launched, which guarantees that information and aspects related to the agriculture can be displayed in the terminal, further to offer effective guidance for some tourists. More than that, by taking advantage of the client terminal, users can also prepare their daily necessaries based on the weather information and tourism information. Accommodation and delicious food can be recommended as well. Under such a development tendency, by applying the internet, tourists can appreciate the views more comprehensively, further to promote the tourism. People cannot only have more fun, but also actually enjoy the differences and fun of the rural areas. Especially for some urban residents, who are confronted by nervous environment, they can relax themselves properly and participate in the agricultural tourism. It cannot merely increase their own values, but also lay a foundation for the modernized information development of agriculture, further to guarantee the well progress and development of the agricultural service ${ }^{[3]}$.

\section{Countermeasures of Constructing the Modern Agricultural Information Service System under the "Internet+" Environment}

\section{Taking Demands of Three Agricultural Issues as the Fundamental Conditions}

Under the "Internet+" environment, it constructs the modernized agricultural information service system. According to the actual development situation and required conditions, the author makes analysis and researches. Three Agricultural Issues mainly refers to agriculture, rural areas and farmers. These three factors are relatively backward in the informatization times. In rural areas, no matter advanced technology, high-level products or innovative consumption concepts, optimized service methods, they cannot satisfy the development requirements of modernized information. Therefore, during the period of setting up the agricultural information service system, it needs to take the demand conditions of Three Agricultural Issues as the foundation, fully study the actual demands of the service objects, further to guarantee effective enforcement of services according to certain standards.

\section{Guaranteeing the Safety of Information Data}

Under the "Internet+"environment, in order to promote the construction of agricultural informatization service system, it needs to guarantee the safety of information data ${ }^{[4]}$. Of which, the realized guarantee offers firewall for the agricultural informatization, so as to ensure that informatization construction project and information network security can be unitedly planned, constructed and maintained during the implementation. Of which, in order to provide efficient guarantee, it is quite important to strengthen the completeness of website and apply the information system normally. During the application period, it cannot only scientifically make disaster preparedness, promote the completeness of network security management, but also prevent virus and manage the loopholes, so as to prevent intrusion, encrypt information and have limited access, further to promote the effectiveness of safety protection measures. Under such a circumstance, it both strengthen the actual protective ability and promote the security supervision of information. It still needs to establish relevant implementation systems, for instance: information security classified protection, risk estimation and network security system. Wit the enforcement of these systems, it guarantees the acquisition, arrangement and transmission of information to be incorporated into reasonable scope, and then ensures that the responsibility subject can conform to relevant standards. 
It still needs to implement supervision and inspection strictly, give full play to the role of organization. By utilizing relevant measures and technologies, it promotes the responsibility shares to be fully implemented and achieves the goal of network information security.

\section{Taking the Innovative Ability as the Core}

In order to improve the business ability on the whole, it needs to take innovative elements as the core. During the construction of modern agricultural information service system, the core elements are mutually related, which are quite important for the development of agricultural informatization. In the meanwhile of classify the businesses, it analyzes the differentiated management mode, analyzes and studies the actual operation cost and management cost. Therefore, it needs to integrate the business ability of enterprises, so as to play its full role. On the basis of integrating businesses, it has to make innovations continuously. By taking advantage of internet and informatization construction, it can change the development of traditional industries. For instance, based on "Moore's Law", it studies the development factors of modern information technology, so as to promote service work well ${ }^{[5]}$.

\section{Taking the Increase of Economic Benefits as Precondition}

During the construction of modern information service system, it contains five business modules. The agricultural informatization construction scheme takes profit as the major factor. However, the actual profit effects are not so good. If the profit ability of enterprises has quite large deficiencies, they cannot support the construction, or realize the large-scale development or multi-level progress. Internet has been applied and developed in all industries, which has quite obvious economic development profits. The utilization of capital chain is still largely restricted. Currently, the business plates of enterprises have been updated. All businesses have realized virtuous cycle. Meanwhile, due to the support of industrialization and the implementation of all subsidy policies, the agricultural economy has been efficiently improved. On the basis of enabling farmers to obtain benefits, it has also provide quite large economic benefits and social benefits for the application of modern agricultural information service system.

\section{Summary}

Based on the above analysis, the integrated development of "Internet+" and agriculture has realized new concept. Under such a background, it has provide efficient implementation strategies for the development of modern agriculture, build quite good brands for the agricultural development, set up a comprehensive big data system for China and realize the new development fields and efficient service work.

\section{References}

[1] Qin Kaida, Zhao Shuai, Qin Cuiping, etc. Analysis on the Selected Model and Route of Leading Industries under the Tendency of "Internet+ Modern Agriculture”, Science \& Technology Progress and Policy, 2016,33(12):67-72.

[2] He Hongxia, Wei Honghei, Researches on the Rural E-commerce Development of Chiping under the Condition of “Internet+" Modern Agriculture, To Explore the Scientific, 2016(11):179-180.

[3] Wei Guoqiang. Practice and Thoughts on the "Internet+" Modern Agricultural Action of Henan, Seed Industry Guide, 2016(7):5-8.

[4] Xu Yuanming, Meng Jing, Zhao Jinchun, etc. Agricultural Internet of Things: Implement the Technological Support of "Internet+ Modern Agriculture"--Investigation based on Demonstration Application of Jiangsu Agricultural Internet of Things, Modern Economic Research, 2016(5):49-53. 
[5] Li Shengjun. Whole Industry Chain Integrated Structure and Mode of "Internet+ Modern Agriculture”, Journal of Hubei University of Economics, 2016,14(3):11-17. 